\begin{tabular}{|c|c|}
\hline & Volume \& Issues Obtainable at The Women University Multan \\
& Annals of Social Sciences and Perspective \\
& ISSN: 2707-7063, Volume 2, No.2 December 2021 \\
\end{tabular}

\title{
Analyzing the Link between Distributed Leadership and Teachers' Self- Efficacy Beliefs at Secondary School Level
}

\author{
Hakim Ali ${ }^{1}$, Saba Akram², Muhammad Hafeez ${ }^{3}$
}

${ }^{1}$ Associate Professor, Department of Education, Government Wilayat Hussain Islamia Graduate College, Multan

${ }^{2}$ Institute of Southern Punjab, Multan, Punjab, Pakistan

${ }^{3}$ Lecturer, Department of Education, Government Wilayat Hussain Islamia Graduate College, Multan

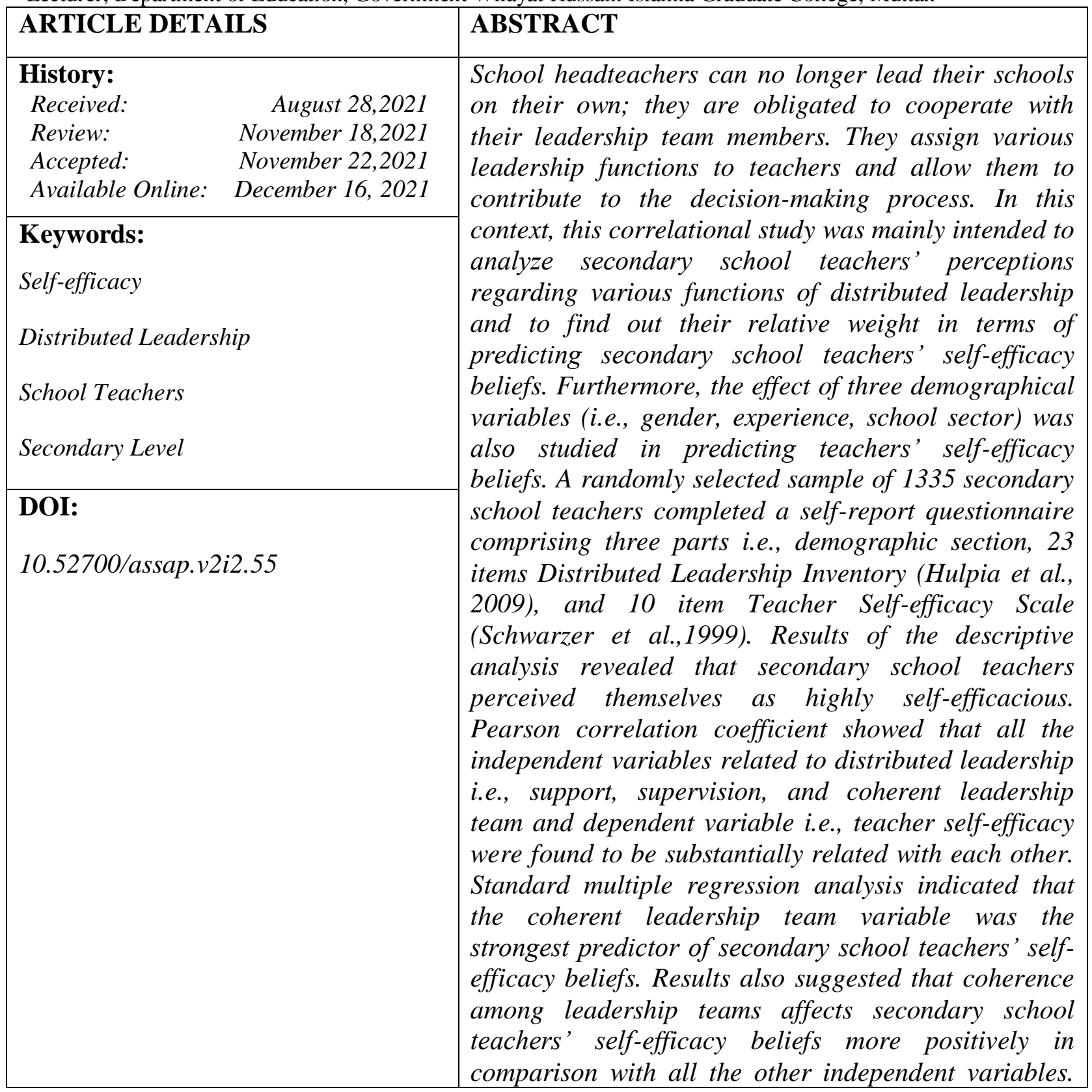




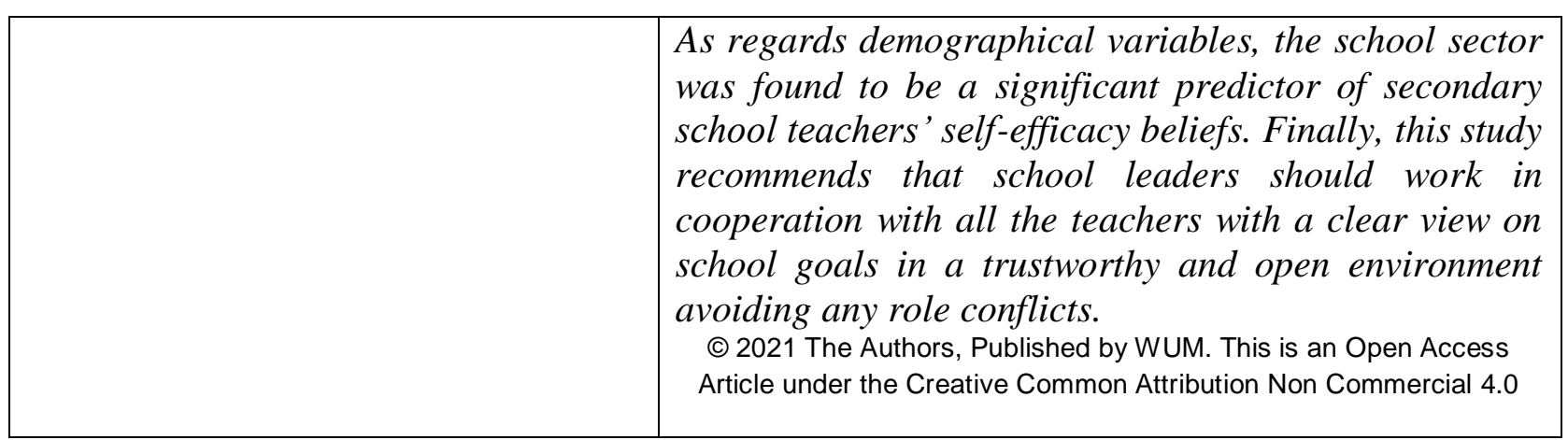

Corresponding author's email address: hakimaliwhisl@gmail.com

\section{Introduction}

School headteachers specifically in secondary schools can no longer lead their schools on their own. They are obligated to cooperate with their leadership team members i.e., teachers to efficiently lead their schools and to cope with multidimensional and complicated institutional tasks in specific school settings (Harris, 2013). They assign various leadership functions to teachers and encourage the whole school team to contribute to the decision-making process (Hulpia et al., 2009). This concept of distributed leadership has got great attention worldwide for the enhancement and betterment of school effectiveness for many decades. The concept is accepted incredibly for schools in most countries to develop the unified potential for change (Harris, 2013; Spillane, 2012; Liu et al., 2018). Similarly, research has constantly indicated that a greater degree of teacher self-efficacy contributes to better institutional performance and student learning (Klassen \& Tze, 2014; Wu et al., 2019; Zee \& Koomen, 2016). This study, therefore, focused on analyzing the distribution of leadership functions and coherence of school leadership teams as likely predictors of secondary school teachers' self-efficacy beliefs.

Distributed leadership, because of Spillane (2012), is a procedure that focuses on the relations among leaders, team members, and the circumstances whereupon the relationships occur. Writing in the same vein, numerous earlier scholars (i.e., Liu \& Werblow, 2019; Spillane, 2006) consider distributed leadership as a structure of leadership that enables leaders to create an atmosphere that drives to increase shared accountability for leadership and allows teachers to work to achieve improved learners' outcomes. Spillane (2006) further explained that in the structure of distributed leadership, leadership is extended into the work of multiple leaders both informal positions and informal positions. Another perspective of distributed leadership, because of Harris and DeFlaminis (2016), is that leadership involves an interactive and collaborative attitude through which institutions are retained, problems are settled and practice is made. Likewise, Bolden (2011) proclaimed that the distribution of leadership functions is not a substitute for different structures or forms of administration but instead gives the space to coordinate different methods in an orderly way.

\section{Literature Review}

Likewise, Liu (2016) declared that distributed leadership substantially concentrates on leadership improvement, especially educator level leadership, and makes easier the enhancement of leadership growth experiences accessible in school surroundings (Szeto \& Cheng, 2017). It has been a more strong facilitator of the division of leadership inside schools (Harris, 2008); can lessen the amount of work for school leaders in official leadership character (Liu et al., 2021) and consequently, boosts institutional decision making (Harris, 2008). 
Moreover, in some school settings, distributed leadership has demonstrated additional reinforcement or strength of leadership impact (Hargreaves \& Fink, 2009).

Furthermore, distributed leadership has proved useful in improving staff capability and teacher productiveness. Leithwood et al. (2017) stated that distributing a greater amount of leadership tasks to teachers certainly influences their competence and involvement in leadership functions. Harris (2009) supported this notion and explained that teacher performance was found to be improved when teachers were more embedded and engaged in the decision making process through a better distribution of leadership functions. Liu and Werblow (2019) found a positive relationship among distributed leadership, teachers' academic optimism, efficiency, and a good working environment. Harris (2009) also proclaimed that the distribution of leadership functions focuses more on the connection between educator input, decision-making approaches, and institutional betterment.

As regards the concept of self-efficacy, it refers to a process of determining how people feel, think, inspire and act (Bandura, 1998); and a person's belief in his/her ability to provide appropriate attitude and performances (Bandura, 2006). Self-efficacy identifies that how well an individual behaves or persists when faced with a problem or obstacle (Bandura, 2006). Teacher self-efficacy encapsulates his/her trust in performing specific pedagogy and student learning activities in classrooms (Jacques, 2017; Zee \& Koomen, 2018). Teacher self-efficacy was found to have the foremost impact on the teaching techniques of teachers as well as the willpower and success of their learners (Klassen \& Tze, 2014; Schwerdtfeger et al., 2008; Tschannen-Moran et al., 2009). Furthermore, Tschannen-Moran et al. (2009) termed teacher efficacy as an opinion of one's competencies to gain requisite results. Research has constantly revealed that a greater degree of teachers' self-efficacy contributes to better students and institutional success in the school settings (Klassen \& Tze, 2014; Wu et al., 2019; Zee \& Koomen, 2016, 2018).

Self-efficacy plays a major and important role in approaching obtaining goals, struggling for them, accomplishing tasks, and overcoming obstacles (Bandura, 1998). Tschannen-Moran et al. (2009) further explained the usefulness of teacher self-efficacy and emphasized that it improves teachers' confidence level in executing and accomplishing certain tasks and assignments related to pedagogy and classroom teaching (Klassen \& Tze, 2014). In educational leadership, a lot of debate has been made to get a better understanding of how school leadership can boost, directly and indirectly, teachers' performance, their self-efficacy beliefs, morale, job satisfaction, and loyalty (Olsen, 2008). Supporting the beneficial role of distributed leadership in the enhancement of employees' self-efficacy beliefs, Jacques (2017) highlighted that both are positively correlated.

Writing in the same vein, Angelle and DeHart (2011) postulated that collaboration and teamwork through distributed leadership had a positive influence on the successful change in an institute. Spillane (2006) made clear the possible influence of distributed leadership on teacher self-efficacy. Spillane (2006) further asserted that the concept of distributed leadership is an opinion that can be used to emphasize learning and teaching and possible plan for school improvement. Enjoying a leadership position as a teacher may increase self-efficacy and these leadership positions pave a path for educators and are budding a way to bring transformational, independent, and distributive leadership in school settings (Jacque, 2017). Distributed leadership is linked with teacher motivation (Liu \& Werblow, 2019); and consequently with teacher self-efficacy. 
Gender is considered an important variable that may affect, in a certain manner or differently, teachers' professional lives in general and their visions about efficacy in particular. A range of contrasting research findings exists with the conclusion that gender affects teacher selfefficacy. Various previous researchers identified a relationship between gender and teacher self-efficacy beliefs (Gurbuzturk \& Sad, 2009; Hamurcu, 2006; Tabak et al., 2003). Some other studies, however, indicated the insignificant influence of participants' gender and teacher self-efficacy beliefs (Chacon, 2005; Karimvand, 2011; Mitchual et al., 2010). Likewise, Mitchual et al. (2010) and Chacon (2005) concluded that generally, the self-efficacy beliefs of teachers were insignificantly differing in accordance with gender. On the contrary, Tabak et al. (2003) indicated a greater degree of self-efficacy beliefs amongst female educators compared with their male fellows. Female educators were found to possess a higher level of self-efficacy than male educators (Gurbuzturk \& Sad, 2009; Sarfo et al., 2015).

Teaching experience is another important variable that is expected to affect teacher selfefficacy beliefs. Wolters and Daugherty (2007) found that teachers during the first year of teaching declared substantially lower self-efficacy regarding instructional practices and classroom administration than more experienced teachers. In contrast, Weinstein (1988) concluded that beginner teachers were found to have a higher level of personal and professional efficacy. Soodak and Podell (1997) reported that teachers with more years of experience opposed more towards change in their personal efficacy beliefs than less experienced teachers. Tweed (2013) found that teachers' gender and their teaching did not play any substantial role in their self-efficacy beliefs.

The previous review of the literature suggests that the distribution of school leadership functions essentially improves teachers' self-efficacy beliefs (Jacques, 2017) and institutional performance (Wu et al., 2019). A review of literature further puts forward that empirical evidence analyzing the relationship between the distribution of school leadership functions and secondary school teachers' self-efficacy beliefs is still scarce particularly in the Pakistani context. For example, Nawab and Asad (2020) examined secondary school principals' perception of distributed leadership. Teachers' views on their sense of self-efficacy were examined by Shaukat in 2011. Likewise, Shaukat and Iqbal (2012) examined the role of teacher self-efficacy in learner engagement. Similarly, Shahzad and Naureen (2017) analyzed the influence of teacher self-efficacy on secondary school students' academic achievement. Because of this background, this study focused on analyzing this relationship by examining the secondary school teachers' perception of distributed leadership and teachers' self-efficacy beliefs. In addition, the effect of participants' demographic characteristics (i.e., gender, teaching experience) along with one structural school variable (i.e., school sector) on teachers' self-efficacy beliefs was analyzed.

\section{Present Study}

The current study was mainly intended to analyze secondary school teachers' perceptions regarding various functions of distributed leadership i.e., supportive function, supervisory function, and coherence of leadership team along with teachers' self-efficacy beliefs. Furthermore, this study was also designed to determine the leadership variables and context variables that influence teachers' self-efficacy beliefs. In this context, the following three research questions were set forth. 
1) How do secondary school teachers perceive the coherence among the leadership team and various functions of distributed leadership i.e., supportive leadership function and supervisory leadership function?

2) How do secondary school teachers perceive their own self-efficacy beliefs?

3) Is there any relationship between secondary school teachers' perception of the leadership variables (i.e., supportive leadership, supervisory leadership, and coherent leadership team), demographic and structural variables (i.e., gender, teaching experience and school sector) and their own self-efficacy beliefs?

\section{Study Design and Methods}

This co relational study was mainly intended to analyze the link between distributed leadership variables and teachers' self-efficacy beliefs at the secondary school level. The population involved in this study was all the 6957 (male and female) teachers currently serving in 183 public and private secondary schools of district Khanewal (Pakistan). A total of 1864 teachers were selected as a sample using stratified random sampling technique and taking into account the educational network (i.e. public versus private), teachers' gender (i.e. male versus female) and participants' years of teaching experience. Krejcie and Morgan (1970) sample size formula guided the researchers in determining sample size in this study.

Out of 1864 sample participants, a total of 1335 (71.6\% response rate) teachers returned the filled questionnaires. Of these 1335 respondents, $52.5 \%$ were female teachers and $47.5 \%$ male teachers, reflecting almost a proportionate percentage of women to men in secondary school teaching roles in this area. Similarly, 52.6\% were serving in public sector schools and $47.4 \%$ in privately managed secondary schools. The participants' experience as school teachers varied from 01 years to more than 16 years. Table 1 summarizes the details about the demographic characteristics of study participants.

Table 1: Demographic Information of Study Participants $(\mathbf{N}=1335)$

\begin{tabular}{llll}
\hline Variable & Category & $\mathrm{N}$ & \%age \\
\hline \multirow{2}{*}{ Gender } & Female & 701 & 52.5 \\
\cline { 2 - 4 } & Male & 634 & 47.5 \\
\hline \multirow{2}{*}{ School Sector } & Public & 702 & 52.6 \\
\cline { 2 - 4 } & Private & 633 & 47.4 \\
\hline \multirow{3}{*}{ Teaching Experience } & $0-5$ years & 707 & 53 \\
\cline { 2 - 4 } & 6-10 years & 366 & 27.4 \\
\cline { 2 - 4 } & $11-15$ years & 160 & 7.6 \\
\hline
\end{tabular}

A questionnaire comprising three parts i.e., demographic section, Distributed Leadership Inventory (DLI) and Teacher Self-efficacy Scale (TSS) was used for collecting data. The DLI developed by Hulpia et al., (2009) was adapted to analyze teachers' perception about three essential management functions of distributed leadership i.e., support, supervision and coherent leadership team. The TSS including 10 items was adopted from Schwarzer et al., (1999) to analyze teachers' perception of their self-efficacy. The DLI comprises 23 closed-ended items with three sub-scales including distribution of support function with 10 items, distribution of supervision function having 3 items and coherent leadership team dimension with 10 items. All 
the items of both the scales and/or subscales were adopted and/or adapted with minor modifications to make them compatible in the context of Pakistani culture

To validate both the scales and their subscales, researchers first sought experts' opinions from 3 senior educationists and then conducted a small scale pilot study involving thirty three secondary school teachers. Experts suggested some changes in DLI in the Pakistani context which were incorporated accordingly. Thirty three secondary school teachers, both male and female, twenty from public sector schools and thirteen from privately managed schools, participated in the pilot testing. Respondents were asked to fill the questionnaire with a special focus on identifying any vagueness and/or technical hitches in understanding the items/wording in both the scales and their subscales. Participants from both the educational networks were satisfied with the content as well as the face validity of both the scales and their subscales. The reliability values of distributed leadership scale and self-efficacy scale were 0.97 and 0.93 respectively. These calculated Cronbach's alpha values aligned with Cronbach (1951) who indicated that reliability coefficients above 0.6 are appropriate.

Before administering the questionnaire to teachers, the researchers took permission from the respective Chief Executive Officer [CEO] and District Education Officer [DEO] as well as from school headteachers. The researchers administered the questionnaire personally and/or with the help of colleagues to all the 1864 sample teachers in their respective schools during working hours. The entire process of data collection took almost one month to complete. Finally, a total of 1335 (71.6\% response rate) teachers returned the completed questionnaire.

\section{Data Analysis and Results}

To analyze the data, researchers used descriptive statistics (i.e., Mean and SD), inferential statistical technique (i.e., Independent samples t-test) along with Pearson product-moment correlation coefficient, and Standard multiple regression analyses methods. Results are presented in Table 2 to Table 4.

Table 2: Means and Standard Deviations of Participants' Perception Scores for Study Variables

\begin{tabular}{lll}
\hline Study Variables & Mean & SD \\
\hline Distribution of support & 4.12 & 0.98 \\
\hline Distribution of supervision & 4.14 & 0.93 \\
\hline Coherent leadership team & 4.05 & 0.98 \\
\hline Overall distributed leadership & $\mathbf{4 . 1 0}$ & $\mathbf{0 . 9 6}$ \\
\hline Teachers' self-efficacy & 4.30 & 0.92 \\
\hline
\end{tabular}

The results of descriptive statistics for both the independent variables and dependent variables were presented in Table 2. Results for all the three independent variables (i.e., three dimensions of distributed leadership: support, supervision, coherent leadership team) suggest that according to participants' views 'supervision' is a highly distributed factor among school leadership team (Mean $=4.14$ ) followed by 'support' dimension of school leadership (Mean = 4.12) and finally 'coherent leadership team'. This dimension of coherent leadership revealed that secondary school teachers perceived their school leadership team as highly cooperative (Mean = 4.05). Similarly, the results of the descriptive analysis in Table 2 for the dependent 
variable i.e., 'teachers' self-efficacy' showed that secondary school teachers perceived themselves as highly self-efficacious (Mean= 4.30).

Table 3: Relationship between Teachers' Perception of Distributed Leadership and Teacher Self-efficacy

\begin{tabular}{lccccc}
\hline \multicolumn{1}{c}{ Variable } & DL & Support & Supervision & CLT & TSE \\
\hline Distributed leadership (DL) & 1 & & & & \\
Distribution of support & $.950^{* *}$ & 1 & & & \\
Distribution of supervision & $.862^{* *}$ & $.825^{* *}$ & 1 & & \\
Coherent leadership team (CLT) & $.954^{* *}$ & $.869^{* *}$ & $.805^{* *}$ & 1 & \\
Teacher Self-efficacy (TSE) & $.771^{* *}$ & $.755^{* *}$ & $.694^{* *}$ & $.762^{* *}$ & 1 \\
\hline
\end{tabular}

** Correlation is significant at the 0.01 level (2-tailed).

Table 3 exhibits that the Pearson correlation coefficient method was used to find out the relation between teachers' perception of their head teachers' distributed leadership practices and teachers' self-efficacy. Findings in Table 3 indicated that the value of ' $r$ ' between teachers' perception of their head teachers' overall distributed leadership practices and teachers' selfefficacy reached 0.771 which is a moderately positive and significant relationship. Likewise, the values of ' $r$ ' between teachers' perception of their self-efficacy and distribution of support dimension of leadership along with distribution of supervision and coherent leadership team dimensions are $.755, .694$, and .762 respectively which also show a moderately positive and significant relationship. This means that all the independent variables related to distributed leadership i.e., support, supervision, and coherent leadership team, and dependent variable i.e., teacher self-efficacy were found to be substantially related to each other. It can, therefore, be concluded that head teachers' distributed leadership practices have a considerable effect on teachers' self-efficacy. This means that improved distributed leadership practices of headteachers lead to an enhanced level of teacher self-efficacy.

Furthermore, Standard multiple regression analysis was performed to predict secondary school teachers' self-efficacy by distributed leadership variables as well as contextual variables. Teachers' self-efficacy beliefs served as the dependent variable. Variables related to distributed leadership i.e., support, supervision, and coherent leadership team along with demographic variables of gender, years of teaching experience, and structural variable of school sector worked as independent variables.

Table 4: Standard Multiple Regression Analysis Showing the Effect of Distributed Leadership and contextual variables on secondary school teachers' self-efficacy

\begin{tabular}{llllll}
\hline Variable & B & SE B & $\beta$ & t & Sig. \\
\hline (Constant) & 9.379 & .909 & & 10.31 & .000 \\
\hline Distribution of Support & .249 & .038 & .267 & 6.48 & .000 \\
\hline Distribution of Supervision & .388 & .094 & .127 & 4.12 & .000 \\
\hline Coherent leadership team & .380 & .037 & .407 & 10.39 & .000 \\
\hline Gender & .296 & .249 & .020 & 1.19 & .235 \\
\hline Experience & -.072 & .134 & -.009 & -.54 & .589 \\
\hline School sector & 1.751 & .260 & .119 & 6.74 & .000 \\
\hline Adjusted $\mathrm{R}^{2}=.627 ; \mathrm{F}(6,1328)=374.23, \mathrm{p}<.001$ & & & & \\
\hline
\end{tabular}


Table 4 demonstrates that the research model explained $62.7 \%$ of variance in secondary school teachers' self-efficacy beliefs [Adjusted R2 $=627 ; \mathrm{F}(6,1328)=374.23, \mathrm{p}<.001$ ]. Adjusted R2 in this result is quite respectable which suggests that secondary school teachers' selfefficacy beliefs are affected by distributed leadership i.e., support, supervision, and coherent leadership team along with other contextual variables. The result in Table 4 also suggests that the significant predictors in this research model are important contributing factors of secondary school teachers' self-efficacy beliefs.

Table 4 further shows that the coherent leadership team variable made the strongest unique contribution in explaining the dependent variable $(\beta=.407)$. This means that the coherent leadership team dimension of distributed leadership was the strongest predictor of secondary school teachers' self-efficacy beliefs. This result also suggests that coherence among leadership teams affects secondary school teachers' self-efficacy beliefs more positively in comparison with all the other independent variables. The Beta values for the distribution of support variable $(\beta=.267)$ and distribution of supervision $(\beta=.127)$ were relatively lower indicating that these variables made less of a unique contribution in predicting secondary school teachers' self-efficacy beliefs.

As regards structural and demographical variables, the school sector was found to be a significant predictor of secondary school teachers' self-efficacy beliefs. The standardized regression coefficient with a positive value $(\beta=.119)$ suggests that teachers serving in privately managed schools will be more self-efficacious than their counterparts serving in public secondary schools. However, the demographical variable of experience was found to be somewhat negatively influencing secondary school teachers' sense of self-efficacy with a negative value $(\beta=-.009)$ of the standardized regression coefficient. This result implies that secondary school teachers' years of teaching experience have no significant effect on their selfefficacy beliefs. Likewise, the demographical variable of gender with standardized regression coefficient value $(\beta=.038)$, made no significant contribution in predicting secondary school teachers' self-efficacy beliefs.

\section{Discussion}

This study was mainly designed to analyze secondary school teachers' perceptions regarding various functions of distributed leadership i.e., supportive function, supervisory function, and coherence of leadership team along with teachers' self-efficacy beliefs. This study also answered the research gap that exists in leadership literature regarding the analysis of the relationship between the distribution of leadership functions and secondary school teachers' self-efficacy beliefs. This study indicated that distributed leadership had a positive relationship with teachers' self-efficacy like previous researches (Davis, 2014; DeMarco, 2018; Jacques, 2017; Sun \& Xia, 2018). This study also revealed that secondary school teachers consider distributed leadership beneficial and effective practice that could be supportive for them to strengthen their self-efficacy. This is an encouraging finding, specifically, in Pakistani settings.

Results of descriptive analysis put forward that according to the secondary school teachers the supervision is the highly distributed leadership function in their schools followed by support and coherent leadership functions. This result confirms the findings of several previous studies (i.e., Hulpia et al., 2009; Spillane, 2006). Furthermore, secondary school teachers believed that their schools have highly cooperative members in their leadership teams and that all the school leadership team members can reasonably contribute to leadership functions. This study also found that secondary school teachers perceived themselves as highly self-efficacious which is 
consistent with the findings of numerous previous studies (i.e., DeMarco, 2018; Jacques, 2017; Sun \& Xia, 2018).

Study findings based on standard multiple regression analysis further clarified the association between independent variables related to distributed leadership and participants' demographic information and secondary school teachers' self-efficacy beliefs. Interestingly, the coherent leadership team dimension of distributed leadership was the strongest predictor of secondary school teachers' self-efficacy beliefs. This substantial positive correlation between the coherence of the school leadership team and teacher' self-efficacy suggests that the majority of secondary school teachers perceive their school leadership team as a cohesive and goal oriented team with a higher level of self-efficacy. This result is in line with several previous study findings (i.e., Eckman 2004; Hulpia et al., 2009) in which researchers found a significant effect of the cooperative team on school leaders' job satisfaction and teacher self-efficacy beliefs.

Regarding the demographic variables, the school sector was found to be a significant predictor of secondary school teachers' self-efficacy beliefs in this study. It is noteworthy that teachers serving in public sector schools have a lower level of self-efficacy in comparison with teachers serving in privately-managed secondary schools. A likely justification for this finding is that in privately-managed secondary schools in Pakistan, leadership teams comprise members with formal job descriptions as well as defined roles and tasks. These roles, however, in government-owned secondary schools are less clearly defined and generally, the school leaders and teachers perform both the roles i.e., teaching role and an information management role. Furthermore, this study found that participants' gender made no significant contribution in predicting secondary school teachers' self-efficacy beliefs. This result is aligned well with the findings of Chacon (2005), Karimvand (2011) and Mitchual et al., (2010). Likewise, the demographical variable of job experience was also found to be an insignificant predictor of secondary school teachers' self-efficacy beliefs. This finding is in contradiction with the findings of several previous researchers (i.e., Weinstein, 1988); Soodak \& Podell, 1997). Finally, it can be concluded that secondary school teachers' perception of the coherence of leadership team and distribution of support were the main sources of teachers' self-efficacy beliefs.

\section{Conclusion}

School headteachers can no longer lead their schools on their own; they are obligated to cooperate with their leadership team members. They assign various leadership functions to teachers and allow them to contribute to school decision-making. This study mainly focused on examining the teachers' perceived influence of this distribution of management functions on secondary school teachers' self-efficacy beliefs. Based on the findings of this particular study, researchers made the following key conclusions. First, the foremost strong point of the current study is the significant positive relationship between the secondary school teachers' perceived self-efficacy beliefs and distributed leadership variables i.e., support, supervision and coherent leadership team. Second, it was concluded that secondary school teachers' believed that the coherence of leadership team and distribution of support, in comparison with other independent variables, were the main sources for predicting teachers' self-efficacy. Third, the school sector was found to be a significant predictor of secondary school teachers' self-efficacy beliefs but gender and experience made no significant contribution in predicting teachers' self-efficacy. Finally, it is recommended for school leaders that they should work in cooperation with all the 
teachers with a clear view on school goals in a trustworthy and open environment avoiding any role conflicts. Likewise, educational policy-makers must devise policies to provide satisfactory incentives to secondary schools for developing a cooperative leadership team.

\section{References}

Angelle, P. S., \& DeHart, C. A. (2011). Teacher perceptions of teacher leadership: Examining differences by experience, degree, and position. NASSP Bulletin, 95 (2), 141-160.

Bandura, A. (1998). Personal and collective efficacy in human adaptation and change. Advances in Psychological Science, 1 (1), 51-71.

Bandura, A. (2006). Guide for constructing self-efficacy scales. Self-efficacy beliefs of adolescents. Information Age Publishing.

Bolden, R. (2011). Distributed leadership in organizations: A review of theory and research. International Journal of Management Reviews, 13 (3), 251-269.

Chacon, C. T. (2005). Teachers' perceived efficacy among English as a foreign language teacher in middle schools in Venezuela. Teaching and Teacher Education, 21, 257272.

Cronbach, L. J. (1951). Coefficient alpha and the internal structure of tests. Psychometrika, 16 (3), 297-334

Davis, M. D. (2014). The relationship between distributed leadership, school culture, and teacher self-efficacy. Grand Canyon University.

DeMarco, A. L. (2018). The relationship between distributive leadership, school culture, and teacher self-efficacy at the middle school level. Seton Hall University.

Eckman, E.W. (2004). Similarities and differences in role conflict, role commitment, and job satisfaction for female and male high school principals. Educational Administration Quarterly, 40, 366-87.

Gurbuzturk, O., \& Sad, S. N. (2009). Student teachers' beliefs about teaching and their sense of self-efficacy: A descriptive and comparative analysis. Inonu University Journal of the Faculty of Education, 10 (3), 201-226.

Hamurcu, H. (2006). Candidate class teachers' self-efficacy beliefs about science teaching. Egitim Arastirmalari, 24, 112-122.

Hargreaves, A., \& Fink, D. (2009). Distributed leadership: democracy or delivery? In Distributed leadership (pp. 181-193). Springer, Dordrecht.

Harris, A. (2008). Distributed School Leadership: Developing tomorrow's leaders. UK: Routledge.

Harris, A. (2009). Distributed leadership: What we know. In Distributed leadership (pp. 1121). Springer, Dordrecht.

Harris, A. (2013). Distributed leadership: Friend or foe? Educational Management Administration \& Leadership, 41 (5), 545-554.

Harris, A., \& DeFlaminis, J. (2016). Distributed leadership in practice: Evidence, misconceptions and possibilities. Management in Education, 30 (4), 141-146.

Hulpia, H., Devos, G., \& Rosseel, Y. (2009). The relationship between the perception of distributed leadership in secondary schools and teachers' and teacher leaders' job satisfaction and organizational commitment. School Effectiveness and School Improvement, 20 (3), 291-317.

Jacques, M. D. (2017). Distributive leadership's relationship to teacher self-efficacy: An Ecological model.

Karimvand, P. N. (2011). The nexus between Iranian EFL Teachers' self-efficacy, teaching experience and gender. English Language Teaching, 4 (3), 171-183. 
Krejcie, R. V., \& Morgan, D. W. (1970). Determining sample size for research activities. Educational and psychological measurement, 30 (3), 607-610.

Klassen, R. M., \& Tze, V. M. (2014). Teachers' self-efficacy, personality, and teaching effectiveness: A meta-analysis. Educational research review, 12 (1), 59-76.

Leithwood, K., Sun, J., \& Pollock, K. (Eds.). (2017). How school leaders contribute to student success: The four paths framework (Vol. 23). Springer.

Liu, Y. (2016). How leadership is distributed and how it is associated with teaching quality? A cross-country study with the TALIS 2013. Michigan State University.

Liu, Y., Bellibas, M. S., \& Printy, S. (2018). How school context and educator characteristics predict distributed leadership: A hierarchical structural equation model with 2013 TALIS data. Educational Management Administration \& Leadership, $46 \quad$ (3), 401-423.

Liu, Y., \& Werblow, J. (2019). The operation of distributed leadership and the relationship with organizational commitment and job satisfaction of principals and teachers: A multi-level model and meta-analysis using the 2013 TALIS data. International Journal of Educational Research, 96, 41-55.

Liu, Y., Bellibaş, M. Ş., \& Gümüş, S. (2021). The effect of instructional leadership and distributed leadership on teacher self-efficacy and job satisfaction: Mediating roles of supportive school culture and teacher collaboration. Educational Management Administration \& Leadership, 49 (3), 430-453.

Mitchual, S. J., Donkor, F. \& C. (2010). The relationship between self-efficacy beliefs and performance of pre-service teacher interns. Ghana Journal of Education and Teaching, 11, $268-282$.

Nawab, A., \& Asad, M. M. (2020). Leadership practices of school principal through a distributed leadership lens: a case study of a secondary school in urban Pakistan. International Journal of Public Leadership, 16 (4), 411-422.

Olsen, E. M. (2008). Helping teachers believe! An investigation into the relationship between principal leadership behaviors, organizational supports, and teacher efficacy beliefs. University of California, Santa Barbara.

Sarfo, F. K., Amankwah, F., Sam, F. K., \& Konin, D. (2015). Teachers' self-efficacy beliefs: The relationship between gender and instructional strategies, classroom management and student engagement. Ghana Journal of Development Studies, 12 (1- 2), 19-32.

Schwarzer, R., Schmitz, G. S., \& Daytner, G. T. (1999). The teacher self-efficacy scale [Online publication]. Available at: http://userpage.fu-berlin.de/ health/teacher_se.htm

Schwerdtfeger, A., Konermann, L., \& Schönhofen, K. (2008). Self-efficacy as a health protective resource in teachers? A biopsychological approach. Health Psychology: official journal of the division health Psychology, American Psychological Association 27 (3), 358-368.

Shahzad K \& Naureen S (2017) Impact of teacher self-efficacy on secondary school students' academic achievement. Journal of Education and Educational Development 4 (1), $48-72$

Shaukat, S. (2011). Development and validation of in-service teachers' self-efficacy beliefs in the context of Pakistan. Evaluation \& Research in Education, 24 (2), 121-141.

Shaukat, S., \& Iqbal, H. M. (2012). Teacher self-efficacy as a function of student engagement, instructional strategies and classroom management. Pakistan Journal of Social and Clinical Psychology, 9 (3), 82-85.

Soodak, L. C., \& Podell, D. M. (1997). Efficacy and experience: Perceptions of efficacy among pre-service and practicing teaches. Journal of Research and Development in Education. 30, 214-239. 
Spillane, J. P. (2006). Towards a theory of leadership practice: A distributed perspective. In Rethinking Schooling (pp. 208-242). Routledge.

Spillane, J. P. (2012). Distributed leadership (Vol. 4). John Wiley \& Sons.

Sun, A., \& Xia, J. (2018). Teacher-perceived distributed leadership, teacher self-efficacy and job satisfaction: A multilevel SEM approach using the 2013 TALIS data. International Journal of Educational Research, 92 (1), 86-97.

Szeto, E., \& Cheng, A. Y. (2017). Developing early career teachers' leadership through teacher learning. International Studies in Educational Administration, 45 (3), 45-64.

Tabak, R. S., Akyildiz, N. \& Yildiz, S. (2003). Teachers' self-efficacy perception levels and environment awareness. Egitim Arastirmalari, 10, 134-145.

Tschannen-Moran, M., \& McMaster, P. (2009). Sources of self-efficacy: Four professional development formats and their relationship to self-efficacy and implementation of a new teaching strategy. The elementary school journal, 110 (2), 228-245.

Tweed, S. (2013). Technology implementation: Teacher age, experience, self-efficacy, and professional development as related to classroom technology integration (Doctoral dissertation, East Tennessee State University).

Weinstein, C. S. (1988). Pre-service teacher's expectations about the first year of teaching. Teaching and Teacher Education, 4, 31-40.

Wolters, C. A.,\& Daugherty, S. G. (2007).Goal structures and teachers' sense of efficacy: Their relation and association to teacher experience and academic level. Journal of Educational Psychology, 99, 181-193.

Wu, W., Wang, H., Zheng, C., \& Wu, Y. J. (2019). Effect of narcissism, psychopathy, and Machiavellianism on entrepreneurial intention-The mediating of entrepreneurial self-efficacy. Frontiers in Psychology, 10 (1), 360-360.

Zee, M., \& Koomen, H. M. (2016). Teacher self-efficacy and its effects on classroom processes, student academic adjustment, and teacher well-being: A synthesis of 40 years of research. Review of Educational research, 86 (4), 981-1015.

Zee, M., Koomen, H. M., \& de Jong, P. F. (2018). How different levels of conceptualization and measurement affect the relationship between teacher self-efficacy and students' academic achievement. Contemporary Educational Psychology, 55 (1), 189200. 